\title{
Microcontroller based Industrial Automation System using Temperature Sensor and Output Logic Control
}

\author{
Tanvir Zaman Khan \\ Dept. of ICE \\ Noakhali Science and Technology \\ University \\ Noakhali-3814, Bangladesh
}

\author{
Apurba Adhikary \\ Dept. of ICE \\ Noakhali Science and Technology \\ University \\ Noakhali-3814, Bangladesh
}

\author{
Md. Ashikur Rahman Khan \\ Dept. of ICE \\ Noakhali Science and Technology \\ University \\ Noakhali-3814, Bangladesh
}

\begin{abstract}
In Automatic temperature controlled system as an microcontroller based embedded system is quiet interesting as well as very essential in the modern era. The basic and conventional system was manual and electromechanical. That's why functionally it is required to establish an automatic system with control logic. Our proposed system will sense the environmental temperature and will take steps along with this temperature by control of switching fan, heater, air conditioner or fire alarm. Most of the manufacturing industries like chemical, petrochemical, food processing, pharmaceutical etc. temperature is one of the prominent factor to be control. Because in these kinds of industries some products need the required temperature to be maintained at highest priority otherwise the product will fail. So the temperature controller is most widely used in almost all the industries. In this paper, we introduce automatic temperature controller using DS18B20 digital temperature sensor and controller unit using PIC16F877A microcontroller with various useful and critical conditions. Supervisory Control and Data Acquisition System (SCADA) is widely used in industrial automation system. We have already performed our system to operate as the way of SCADA and it can detect measuring parameters in real time operation and send it to the control station. If these parameters are not in sustainable level, it sends an alarm and indicating signal in control station rather than taking any kind of intelligent decision. But our proposed system can perform better than SCADA in real time operation with determining intelligent decision on the basis of real time situation. We used a Microcontroller to determine and processing the predefined system decision as like artificial intelligence system. Field of operation of our system can be extended by including more process parameter to operate this automation system.
\end{abstract}

\section{Keywords}

Microcontroller, PIC16F877A, Temperature Control, Embedded System, Industrial Automation.

\section{INTRODUCTION}

In Embedded System design there is no limit of developing. Newer forms of sensors as well as program syntax are being invented day by day. The more effective system is being developed as well [1]. This paper is focused on basically a microcontroller based temperature indicator system which displays temperature in the range of $-55^{\circ} \mathrm{C}$ to $+125^{\circ} \mathrm{C}$ in $0.5^{\circ} \mathrm{C}$ incremental accuracy. It continuously senses temperature, displays it, compares it with set value. If it's less/ greater, then it controls the heat, produce by heating element or controls the temperature by switching on $\mathrm{AC} / \mathrm{fan}$. It includes both software and hardware design. Before proceeding to the design, introduction to some parameter is needed [1] [2]. The heart of this system is microcontroller. It is a device which has the same characteristics as that of an entire computer system. A microcontroller has a processor, RAM, ROM, I/O ports external clock input etc. [3]

Temperature controlled system includes software with hardware. As it processes only digital logic, design should be made carefully to make sure that there is no undefined state as well as infinite level of voltage [4]. Other component interfacing with the microcontroller is a very important part. Microcontroller output should not be used with load directly. If the load impedance is low and is connected with the MCU directly, the output may be shorted with ground which may led the total system to an unstable state. The connection from sensor to the MCU should be firm because any fluctuation of voltage may cause false triggering. The MCU runs only voltages ranges from $4.0 \mathrm{~V}$ to $5.5 \mathrm{~V}$. Care should be taken for keeping the voltage constant in that range. Microcontroller makes the transistor switching and relay operates from different power supply. We have to ensure to make the ground same for different power supply otherwise the system may not work properly [4] [5].

\section{PROPOSED SYSTEM}

At first the sensor DS18B20 will sense the current environment temperature and will be shown in LCD display. Then it will apply the specific port of microcontroller to control the temperature by operating our heater, cooler, Air Conditioner, alarm etc. Temperature range can be set through microcontroller programming. The microcontroller oscillation frequency $8 \mathrm{MHz}$. 4-bit interfacing of LCD is used. By comparing the predefined temperature value, when it $<20$ degree Celsius then the heater is turned ON. After then when temp goes above temp, heater is turned OFF. Again if temp goes $>250 \mathrm{C} \& \&<360 \mathrm{C}$ the corresponding relay switch On the Fan/ Air cooler [6]. If temp goes above critical temp (which can be changed by user demand) there is an alarm system which sounds. It is also showing indicating light for different temp suggestion [5] [6].

A microcontroller cannot read programs by itself, so we have to develop its program with the help of IDE (Integrated Development Environment). The I/O lines and other options of microcontroller are configured through programming for specific purpose. Programs have been written in ANSI C and Assembly language. The IDE converts the program into Machine code called HEX file (extension “.hex”). As the microcontroller executes a single line at a time, the program should have the path to access all other functions. For this project we have compared the predefined standard temperature value [6]. 
There are two parts of automatic temperature controller

1. Temperature sensing

2. Temperature controlling

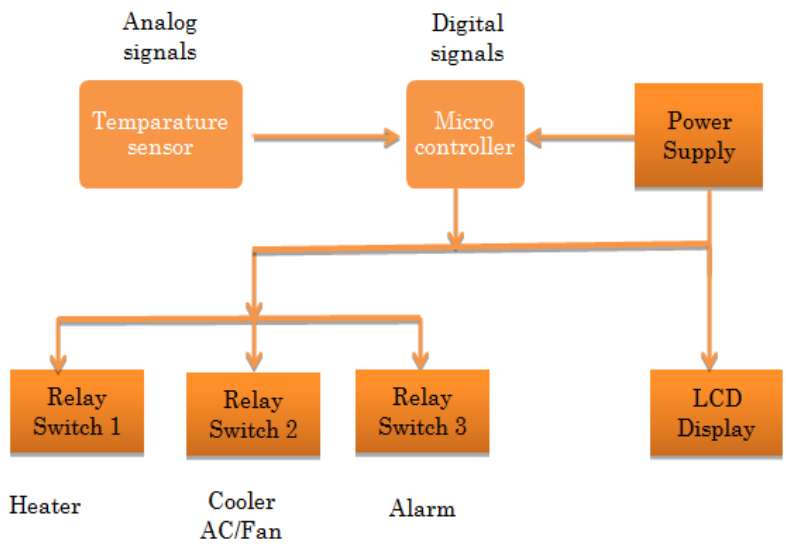

Fig 1: Block diagram of automatic temperature controller

\section{SOFTWARE AND HARDWARE COMPONENTS}

A program is developed for the microcontroller on the basis of an algorithm. First of all we implemented sensor circuits to take input from the outer environment like ambient temperature. The DS18B20 sensor is connected in RE2 (PORT E is a bidirectional I/O port) pin. It is Chip select control for Parallel Slave Port. MCU receives a serial Binary data from the 1-wire sensor and comparing the input signal to give output.

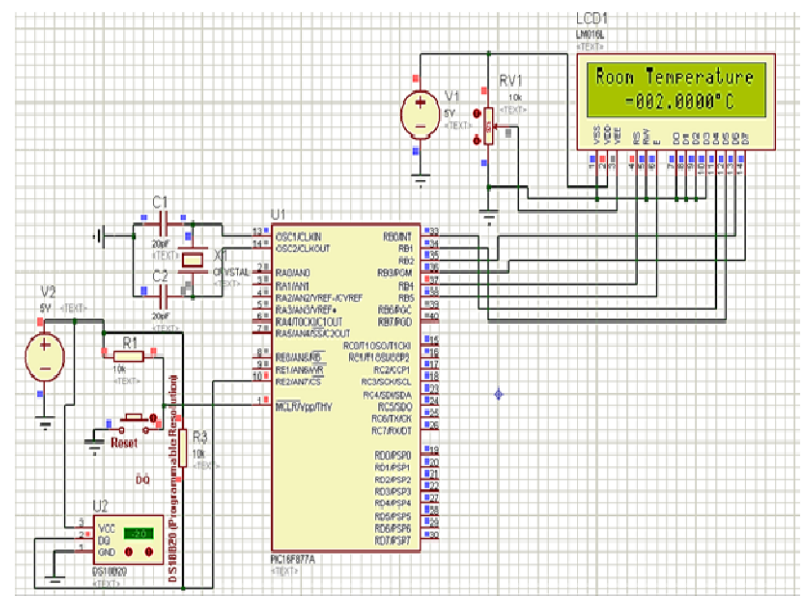

Fig 2: Simulation Model of Microcontroller and Sensor.

Then we send binary input to output pin for corresponding logical program. The RD2-PD7 is set to output port. These output ports are connected to transistor driver to drive different controllable equipment. The program is simulated in Micro C Pro simulator \& converted into a hex file to load in microcontroller as well [3] [6] [7] [8].

\subsection{PIC16F877A Microcontroller}

For this project, PIC16F877A microcontroller is used. This CMOS device has powerful processor which can execute 200 nanosecond instructions though it has only 35 single word instructions that are easy-to-program. This microcontroller is 8-bit FLASH-based packs Microchip's with powerful PIC® architecture into an 40 pin package. This PIC16F877A microcontroller is equipped with 256 bytes of EEPROM data memory which is capable of self-programming. It also has an ICD, 8 channels of 10-bit Analog-to-Digital (A/D) converter, 2 Comparators, 2 compare/capture/PWM functions. The synchronous serial port of PIC16F877A can be configured as either a Universal Asynchronous Receiver Transmitter (USART) and 2-wire Inter-Integrated Circuit $\left(\mathrm{I}^{2} \mathrm{C}\right)$ bus or 3wire Serial Peripheral Interface (SPI) [3] [7]. These prominent features make this microcontroller ideal for more advanced level A/D applications in industrial, consumer applications, automotive and appliances.

\subsection{DS18B20 Temperature Sensor}

The DS18B20 temperature sensor will be used as a digital thermometer which provides 9-bit to 12-bit Celsius temperature measurements. It also has an alarm system featured with nonvolatile user-programmable upper and lower trigger points. The communication of DS18B20 performs over a 1-Wire bus. In other words it requires only one data line (and ground) with a central microprocessor. It has unique 1Wire Interface Requires Only One Port Pin for Communication. It has an operating temperature range of-55C to $+125^{\circ} \mathrm{C}$ and is accurate to $\pm 0.5^{\circ} \mathrm{C}$ over the range of $-10^{\circ} \mathrm{C}$ to $+85^{\circ} \mathrm{C}$ [8]. In addition, the DS18B20 has a special feature of deriving power directly from the data line. This is called parasite power. This feature eliminates the need for an additional power source. Multiple DS18B20s can be performed on the same 1-Wire bus due to a unique 64-bit serial code of each DS18B20 temperature sensor. Thus a single microprocessor can control many DS18B20s spread over a huge area. Lots of applications can be benefitted from this feature including temperature monitoring systems inside buildings, equipment, or machinery, HVAC environmental controls, control systems and process monitoring [8] [9].

\subsection{LCD Module}

A $16 \times 2$ LCD display is used with 4 bit connection to the microcontroller. LCD display is used only for display the temperature status. Various circuits and devices are commonly used $16 \times 2$ LCD display module for its simplicity and low cost. This module has enormous advantages over multi segment LEDs and seven segment display. It can display custom character, special character, animation and so on. LCDs are also easily programmable. A $16 \times 2$ LCD means it must be capable of displaying 16 characters per line and 2 lines must be in the display. In this LCD each character is displayed in $5 \times 7$ pixel matrix. Command and data are the two registers of this LCD. The command instructions are stored in the command registers and transfer to the LCD. This command instruction executes different task including screen clearing, initializing LCD, controlling display, setting the cursor position etc. The data which are ASCII value of the character stored in the data register and to be displayed on the LCD [10].

\subsection{Relay}

A relay is an electrical controllable switch that operates under the mechanism of another electrical circuit. Relay usually attached to the microcontroller output pins and used to turn on/off high-power devices such as transformers, bulbs, motors, heaters, etc. Sensitive components are commonly placed away from these devices. The operational mechanisms of different types of relay are almost same. Relay is activated by an electromagnet to open or close when current moves through the coil. Similar to auto couplers, there is no galvanic connection (electrical contact) between input and output circuits. To launch the operation of relay it requires both higher current and higher voltages but there are also miniature 
ones that can be activated by low current directly acquired from output pins of the microcontroller.

\section{PROGRAMMING AND ALGORITHM} Algorithm 1 (Sensing the Ambient Temp. with DS18B20) Input Sensor at PORTE, 2

One wire reset signal

Issue command SKIP_ROM

Issue command CONVERT_T

(To initiate a temperature measurement and A-to-D conversion, the MCU must issue a Convert T [44h] command)

Issue command SKIP_ROM

Issue command READ_SCRATCHPAD

temp $=$ Ow_Read $(\& P O R T E, 2) ;$

temp $=\left(\right.$ Ow_Read $_{2} \&$ PORTE, 2$\left.)<<\right)+$ temp;

Display_Temperature(temp); (Format and display result on $L c d)$.

\section{Algorithm 2 (Controlling the Relay) \\ Output relay at PORTE, 4}

Issue command SKIP_ROM

Issue command SKIP_ROM

Issue command LEVEL_HIGH

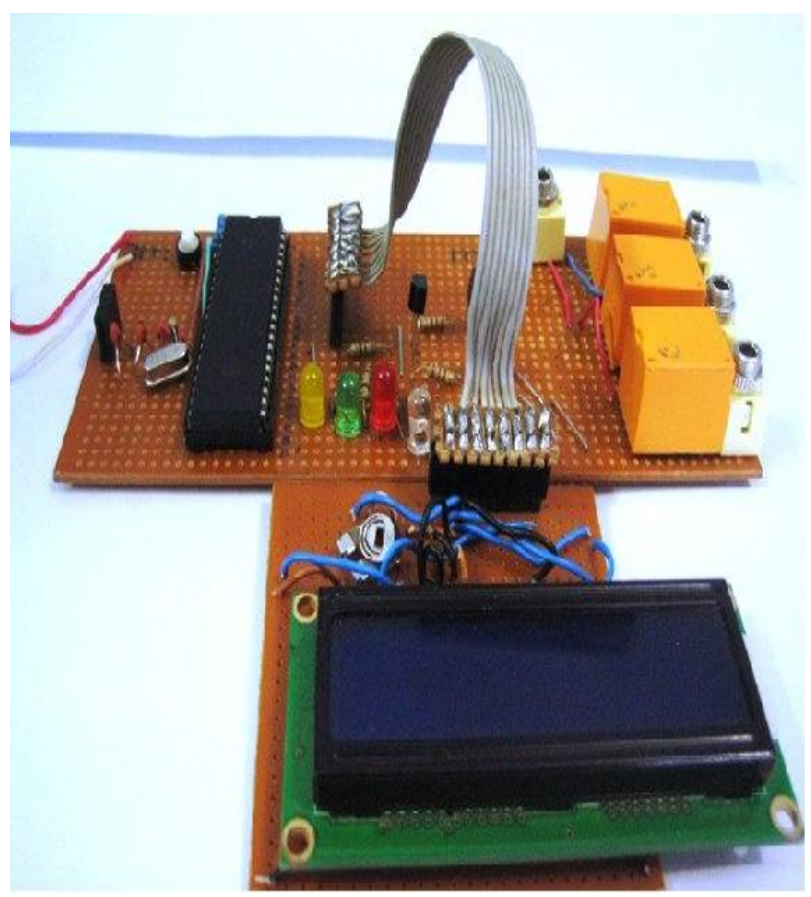

Fig 3: Hardware Setup

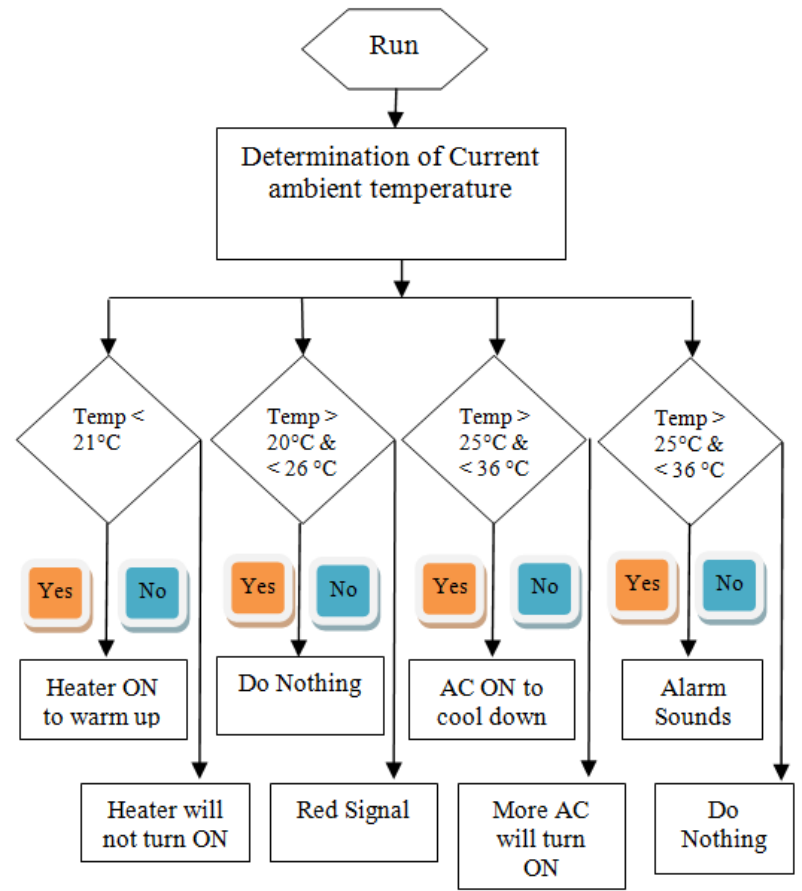

Fig 4: Flowchart of micro module controlling algorithm

\section{RESULT}

This paper is all about an automated temperature control system where DS18B20 sensor will sense the temp and display it on LCD. In practical field, there will be a lot of false triggering and can reset the system. So the sensor should be set carefully. For different temperature range it shows different color LEDs for temp suggestion. With the increase in temp, the system will turn on red LED and corresponding relay drives the Fan/AC. It will operate according to the following output logic and temperature range.

Table 1. Output logic operation of temperature range

\begin{tabular}{|c|c|c|c|}
\hline Temperature & $\begin{array}{c}\text { LCD } \\
\text { Display }\end{array}$ & $\begin{array}{c}\text { Light } \\
\text { status }\end{array}$ & Relay switch \\
\hline$<21{ }^{\circ} \mathrm{C}$ & $18.2345^{\circ} \mathrm{C}$ & Yellow & Heater ON \\
\hline$>20 \& \&<26^{\circ} \mathrm{C}$ & $22.7635^{\circ} \mathrm{C}$ & Green & DO Nothing \\
\hline$>25 \& \&<36^{\circ} \mathrm{C}$ & $30.7823^{\circ} \mathrm{C}$ & Red & Fan/AC ON \\
\hline$>35^{\circ} \mathrm{C}$ & $38.4531^{\circ} \mathrm{C}$ & White & Alarm Sounds \\
\hline
\end{tabular}

\section{CONCLUSION}

In this paper an automation system has been proposed based on microcontroller, sensor and logic control. Microcontroller is the main processing unit; sensor receives the temperature and output logic controls the relay. Again the sensor cannot sense the temp at a long distance within a short time. So, adding more sensors could give more accurate temperature. GSM module and Wireless module could be new feature of this system. By adding this module SMS can be sent to the user when anything goes wrong. Our proposed system has designed on the basis of temperature parameter which is the global variable of any system. If this automaton system needs to be implemented to another automation system, it is required to sense and process other variables of that system as like as temperature. To make sure that the system is automated and safe using output logic control. In the case of SCADA system, 
it is unable to operate in worst case situation during power blackout and unable to isolate the healthy system from affected part of the system. Our proposed system is able to operate during blackout or any kind of worst case situation. It can also isolate the protected system in real time operation or rapidly shutdown the protected system.

\section{REFERENCES}

[1] Kalyan Phani Tangirala, J. Robert Heath,Arthur Radun, Terrance E. Conners, "A handheld programmable-logicdevice-based temperature and relative-humidity sensor, processor, and display system platform for automation and control of industry processes", IEEE Transections on Industry Applications, Vol. 46, no. 4, July/August 2010

[2] Mayur Avhad, Vinit Divekar, Harshad Golatkar, Sanket Joshi, "Microcontroller based automation system using industry standard SCADA", 2013 Annual IEEE India Conference (INDICON)

[3] Myke Predko, Programming and Customizing the PIC Microcontroller, Third edition, McGraw-Hill Education, Sep 25, 2007

[4] Wenlian Li, Yang Li and Fan Xiao, "The Design and Implementation of Digital Temperature Measurement and Automatic Control System", 2010 International Conference on Computer Application and System Modeling (ICCASM 2010)

[5] Shufen LI, Junli LIU, Junqin LIU, "Design on the central air-conditioning Controller Based on Lab VIEW", ICCASM 2010

[6] Milan Verle, PIC Microcontrollers-Programming in C, mikroElektronika; $1^{\text {st }}$ edition (2009)

[7] "PIC16F87XA Enhanced Flash Microcontrollers datasheet”, 2003 Microchip Technology Inc.

[8] Temperature measurement using DS1820 sensor. Use of '1-wire' protocol. [Online]. Available: http://www.mikroe.com/chapters/view/17/

[9] "DS18B20 Programmable Resolution 1-Wire Digital Thermometer datasheet", Maxim Integrated Products, 120 San Gabr iel Dr ive, Sunnyvale, CA 94086 408-7377600

[10] Brown,LCDModuleDatasheet:http://www.engineersgara ge.com/electronic-components/16x2-lcd-module datasheet 